\title{
Xenopus tropicalis
}

National Cancer Institute

\section{Source}

National Cancer Institute. Xenopus tropicalis. NCI Thesaurus. Code C161024.

The Western clawed frog, Xenopus tropicalis. 